\title{
The anatomy of the king crab Hapalogaster mertensii Brandt, 1850 (Anomura: Paguroidea: Hapalogastridae) - new insights into the evolutionary transformation of hermit crabs into king crabs
}

\author{
Jonas Keiler ${ }^{1,2}$, Stefan Richter ${ }^{1}$, Christian S. Wirkner ${ }^{1}$ \\ ${ }^{1}$ Universität Rostock, Institut für Biowissenschaften, Allgemeine \& Spezielle Zoologie, Universitaetsplatz 2, 18055 \\ Rostock, Germany \\ ${ }^{2}$ E-Mail: jonas.keiler@gmx.de
}

Key words: Anomala, carcinization, circulatory system, evolutionary morphology, structural coherence, variability

\begin{abstract}
The emergence of king crabs from a hermit crab-like ancestor is one of the most curious events in decapod evolution. King crabs comprise two taxa, Lithodidae and Hapalogastridae, and while lithodids have formed the focus of various anatomical studies, the internal anatomy of hapalogastrids has never been studied although this group might represent a more ancestral morphological condition within king crabs than lithodids do. To better understand the evolutionary transformation of pagurid-like hermit crabs into king crabs, we studied the hemolymph vascular system and associated organs of representatives of Hapalogaster and present here the first micro-computer tomography data pertaining to the internal anatomy of hapalogastrids. Our results for Hapalogastridae are compared with existing and new data on Paguridae and Lithodidae and are discussed in the light of the process of carcinization or evolutionary transformation into a crab-like habitus. Hapalogaster resembles both pagurids on the one hand and lithodids on the other, not only with regard to external morphological characters but also in terms of certain internal anatomical features. In this and other respects, Hapalogaster represents an evolutionary intermediate form that connects pagurids and lithodids.
\end{abstract}

\section{Contents}

\begin{tabular}{|c|}
\hline ntroduction \\
\hline Material and methods \\
\hline Studied species \\
\hline Resin injection ......................... \\
\hline Fixation and dehydration \\
\hline Micro computer tomography (MicroCT) \\
\hline $3 D$ reconstruction \\
\hline Image management \\
\hline Results \\
\hline External morphology \\
\hline Internal morphology. \\
\hline Discussion ........................ \\
\hline Evidences of a close relationship between \\
\hline 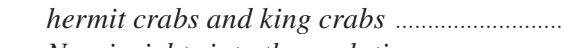 \\
\hline New insights into the evolutionary process \\
\hline
\end{tabular}

Transformations of the pleon 160 Transformations of the ventral cephalothoraxcoherences in the course of carcinization 161 Hapalogaster - the connecting link between hermit crabs and lithodid king crabs? Acknowledgements 163 References 163

\section{Introduction}

The theory of the transformation of 'hermit crabs' into 'king crabs' constitutes the most dramatic instance of the evolution into a crab-like habitus, called carcinization. Superficially at least, hermit crabs and king crabs do not seem to have much in common. A closer relationship between 'hermits' and 'kings', however, has been suggested already in the $19^{\text {th }}$ century (Brandt, 1850; Boas, 1880a, b; Bouvier, 1895). It was Boas (1880a, b) who suggested a closer relationship of pagurid hermit crabs (at that time he used the genus name Eupagurus) and Lithodes and who emphasized the descent of Lithodes from an (Eu-)Pagurus-like ancestor. Bouvier (1895) also favored this close relationship and emphasized the importance of Hapalogaster as a 'forme intermédiaire' between pagurids and lithodids. More recent morphological studies supporting a closer relationship between pagurids and 'king crabs' (Richter and Scholtz, 1994, Reimann et al., 2011; Keiler and Richter, 2011) considered both sub-groups of 'king crabs' which are now categorized as Hapalogastridae and Lithodidae. Although the common name 'king crabs' is often restricted to certain species of Lithodidae (e.g. Stevens, 2014) we use the common name 'king crabs' for all representatives of both taxa. We reject to use Lithodoidea for a superfamily taxon including Hapalogastridae and Lithodidae because this classification camouflages the real phylogenetic relationships (Ahyong et al., 2009; 

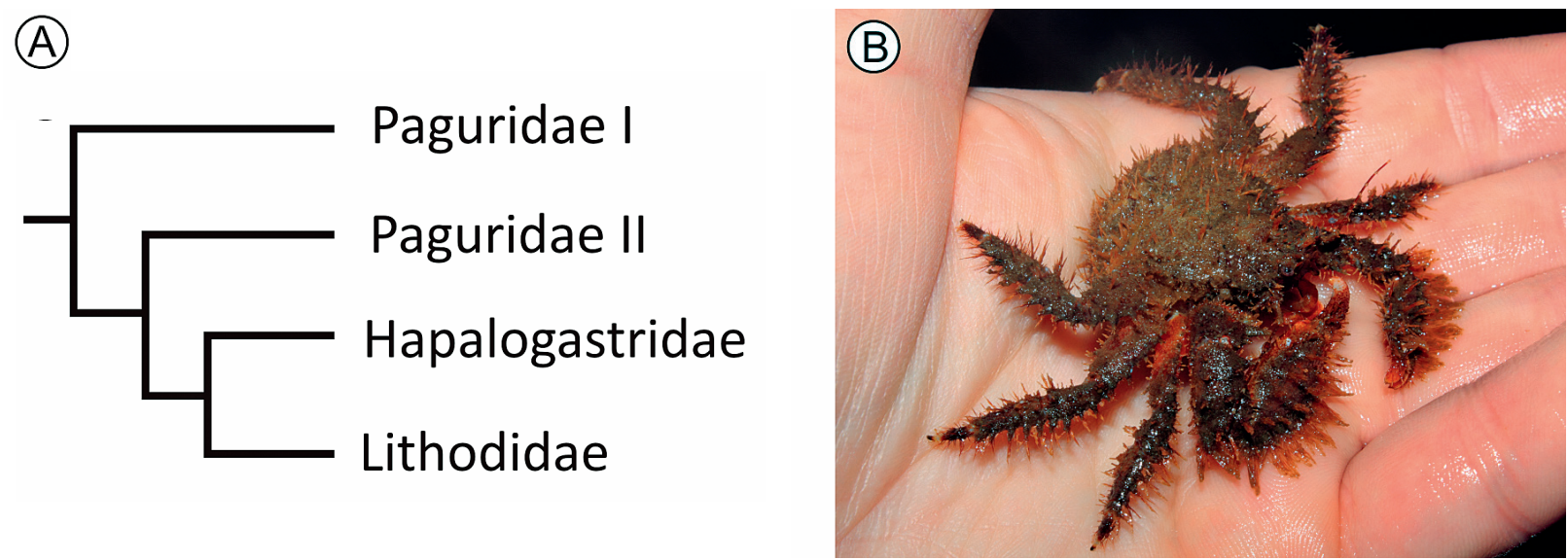

Fig. 1. A. Hapalogaster mertensii, living adult specimen on human hand (photograph provided by Ch. Noever). B. Suggested phylogeny supported by molecular (Ahyong et al., 2009; Schnabel et al., 2011; Bracken-Grissom et al., 2013) and morphological data (Reimann et al., 2011) with paraphyletic Paguridae implying that king crabs (Hapalogastridae + Lithodidae) are derived from a hermit crab-like ancestor.

Keiler et al., 2013; Anker and Paulay, 2013). Molecular analyses of king crabs and hermit crabs started with Cunningham et al. (1992), but like most of the following molecular analyses they did not include representatives of the Hapalogastridae. These analyses, however, have shown that Lithodidae and Paguridae are closely related (Morrison et al., 2002) or that the former is even nested in the paraphyletic latter (Cunningham et al., 1992; Tsang et al., 2008, 2011; Chu et al. 2009). It took more than a decade since the first molecular analysis when hapalogastrids were included in comprehensive molecular analyses on anomurans (Ahyong et al., 2009; Schnabel et al., 2011; BrackenGrissom et al., 2013), confirming paraphyletic Paguridae and a monophylum Hapalogastridae + Lithodidae nesting in the former (see Fig. 1A). Though some authors dispute this phylogenetic hypothesis (McLaughlin et al., 2004, 2007), the majority of data supports the assumption that king crabs are derived from hermit crabs. The transformations, i.e. the evolutionary process of carcinization (Borradaile, 1916; Scholtz, 2014), in the lineage from the pagurid-like ancestor toward king crabs led to the characteristics of a crab-like habitus: a broadened, strongly calcified carapace and a pleon bent under the cephalothorax. Despite the significant differences in their habitus and overall appearance, hermit crabs and king crabs share several morphological characters (Schnabel et al., 2011; Reimann et al., 2011; Keiler and Richter, 2011; Keiler et al., 2013; Jaszkowiak et al., in press), most noticeably the asymmetrical pleon and single-sided left pleopods in females, a condition which has been interpreted as a morphological heritage from the pagurid-like ancestor (Boas, 1880a, b; Bouvier, 1895; Richter and Scholtz, 1994). In a recent comparative study we showed that the morphology of the hemolymph vascular system differs widely between Paguridae and Lithodidae due to morphological changes in the endophragmal skeleton (cuticular invaginations) in the lineage towards lithodids which affected the internal anatomy (Keiler et al., 2013). While Lithodidae, being more easily available, have formed the focus of that and various other anatomical studies, the internal anatomy of the smaller Hapalogastridae (Fig. 1B) has not been studied at all, though it probably represents in many aspects the plesiomorphic morphological condition within king crabs (Richter and Scholtz, 1994). Most prominent is the soft and rarely calcified sac-like pleon in Hapalogastridae which, apart from the lack of uropods, somewhat resembles that of the soft-tailed hermit crabs, first recognized by Brandt (1850). To better understand the evolutionary transformation of hermit crabs into king crabs, we studied the hemolymph vascular system and associated organs of representatives of Hapalogastridae and present here the first data ever published in relation to the internal anatomy of hapalogastrids. Our results for hapalogastrids are compared with existing and new data on pagurids and lithodids and are discussed in the light of the evolutionary transformation of hermit crabs into king crabs. 


\section{Material and methods}

\section{Studied species}

The following species were studied:

Paguroidea Samouelle, 1819

Paguridae Latreille, 1802

Pagurus hirsutiusculus (Dana, 1851)

(San Juan Island, WA, USA, coll. 2010)

Pagurus pubescens Krøyer, 1838

(Svaldbard, Norway, coll. 2012)

Pagurus bernhardus (Linnaeus, 1758)

(Gulmarsfjord, Sweden, coll. 2010)

Hapalogastridae Brandt, 1850

Hapalogaster mertensii Brandt, 1850

(Sitka, Alaska, USA, coll. 2012)

Hapalogaster grebnitzkii Schalfeew, 1892

(San Juan Island, WA, USA, coll. 1953)

Lithodidae Samouelle, 1819

Lithodes santolla (Molina, 1782)

(Chile, coll. 2008)

Lithodes aequispinus Benedict, 1895

(Sitka, Alaska, USA, coll. 2012)

A full list of the specimens studied (which are catalogued and stored in the Zoological Collection of the University of Rostock), and a description of each of the methods used are provided in Supporting Information Table S1.

\section{Resin injection}

The acrylic casting resin Mercox 2-CL (Ladd Research, Williston, VT) or the polyurethane-based casting resin PU4ii (vasQtec, Zurich, Switzerland) was injected into the heart of specimens previously killed using $\mathrm{CO}_{2}$ - or Eugenol-saturated water.

In a first step, the resin was mixed with the appropriate catalyst and placed in a $5 \mathrm{ml}$ syringe (Luer Lock Solo, Braun, Melsungen, Germany) just before use. The resin in the syringe was injected via an injection cannula (diameter 0.3-0.6 mm, Sterican, Braun, Melsungen, Germany) through the carapace into the heart and the specimens were left for several minutes to allow the resin to polymerize and temper.

\section{Fixation and dehydration}

For MicroCT, specimens (injected and non-injected) were fixed in Bouin's fluid for several days, washed and then critical point (EMITECH K850, UK) or freeze dried (Alpha 1-4, Martin Christ, Osterode a.H., Germany; UniCryo MC2L, UniEquip, Munich, Germany).

\section{Micro computer tomography (MicroCT)}

Dried or macerated specimens were mounted with hot glue on a specimen holder. X-ray imaging was performed with a

- Phoenix Nanotom 180 (Phoenixlx-ray, GE Sensing \& Inspection Technologies) high-resolution MicroCT system in high resolution mode using the program datoslx aquisition (Target: Molybdenum, Mode: 0-1; Performance: ca. 8-13 W; number of projections: 7201440; detector timing: 1000-3000 ms; voxelsize ca. 10-30 $\mu \mathrm{m})$. Using the software datos $\mathrm{x}$ reconstruction a volume file was generated, and a stack of virtual sections exported using the software VGStudio Max (Volume Graphics, Heidelberg).

- Xradia MicroXCT-200 X-ray imaging system (Carl Zeiss X-ray Microscopy Inc., Pleasanton, USA) at 20 $\mathrm{KV}$ and $4 \mathrm{~W}$ (10.0 scintillator-objective lens unit, 5-20 $\mu \mathrm{m}$ pixel size).

\section{$3 D$ reconstruction}

For all 3D reconstructions, the software Imaris 6.4.1 and 7.0.0 (Bitplane) was used (for details of the process see Keiler et al., 2015).

\section{Image management}

All figure plates were arranged using Corel Graphics Suite X3 (Corel, Ottawa). Bitmap images were embedded into Corel Draw X3 files and digitally edited with Corel PhotoPaint X3.

\section{Results}

\section{External morphology}

Hapalogaster mertensii (Fig. 1B) and H. grebnitzkii have a carapace wider than long (proportions illustrated in Fig. 2DII). The pleon is bent under the cephalothorax (Fig. 2B, C, I), the fourth to six pleonal segments together forming the barely calcified sac-like posterior portion of the pleon (Fig. 2B, I), hidden in dorsal view (Fig. 2A). The overall body shape is fairly oval (Fig. 2A, DII). In females, the pleonal tergites (Fig. 2B) are arranged asymmetrically and pleopods (Fig. 2C) are present on the left side only. In males, the pleonal tergites are arranged fairly symmetrically (Fig. 2I) and pleopods are absent. The fourth to seventh thoracic sternites are fused into a sternal plate, the so-called 

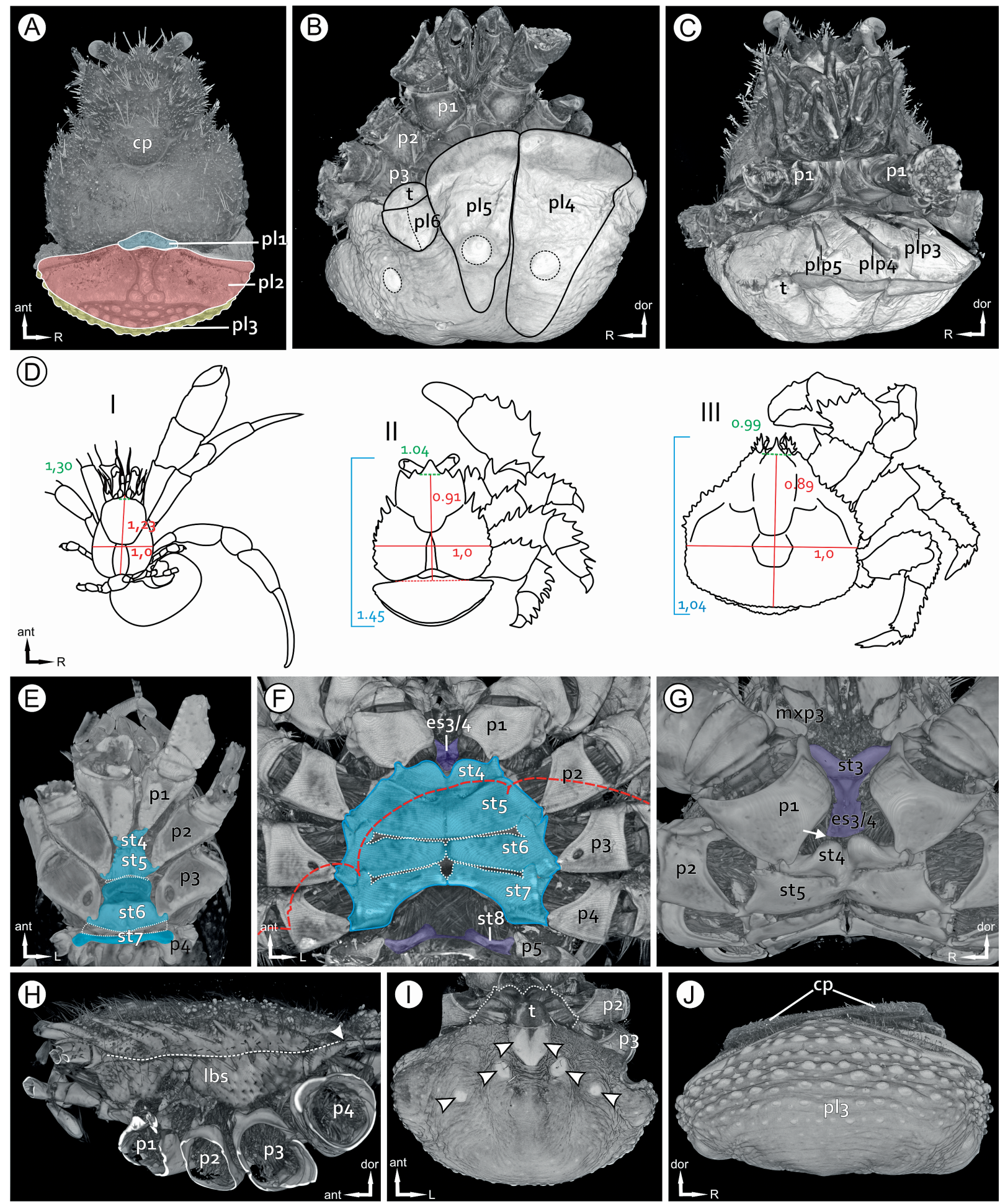
plastron (Fig. 2F), which is roughly semioval in ventral view and has a markedly semicircular posterior emargination (Fig. 2F). The plastron is largely covered by the bent pleon (Fig. 2B). The calcification of the plastron is incomplete: the sixth and seventh thoracic sternites are distinctly delimited by a broad median and transverse suture; the third thoracic sternites, which are not part of the plastron, are likewise delimited by a suture (arrow, Fig. 2G), and bent dorsally. The eighth thoracic sternites are distinctly separate from the plastron (Fig. 2F).

\section{Internal morphology}

In the following, the descriptions of soft tissue structures (most inner organs) are restricted to H. mertensii, while in $H$. grebnitzkii only integumental structures were studied.

The digestive system. The stomach (stc) is situated dorsally in the anterior portion of the cephalothorax, from where the gut extends as a tube into the telson (Fig. 3A-C). A pair of anterior ceca (ce) emanates dorsally from the pylorus (Fig. 3C). A posterior cecum is not present. The hepatopancreas (hp) fills most of the pleon and is formed by two clusters of tubular diverticles which are connected to the pylorus on each side via a main duct (Fig. 3B, C).

The antennal glands. The antennal glands (ag) are located anterolaterally in the cephalothorax near the second antennae and are dorsally connected to the antennal bladder (bl; Fig. 3D, E). The sponge-like lobes of the bladder fill most of the cephalothorax and reach into the pleon (Fig. 3A, B, D, E).

The reproductive system. The gonads (ovaries and testes) are paired and mainly located in the pleon laterally to the gut (Figs. 3A, 4D, G) and dorsally to the hepatopancreas.

The endophragmal skeleton. The endophragmal skeleton consists of paired endosternites (es) and endopleurites - cuticular invaginations located between two contiguous thoracic segments. Two thin transverse thoracic bridges (tb) connect the paired endosternites $4 / 5$ and $5 / 6$, respectively, and span the ventral portion of the cephalothorax (Fig. 5B). The endosternites 7/8 form the posterior edge of the plastron and are bent anteriorly.

Ventral thoracic muscles. The ventral thoracic muscles (vtm) are extrinsic muscles of the pereiopods and are located directly above the plastron. The muscles of the fourth to seventh thoracic segments, which correspond to the chelipeds, p1, and the walking legs, p2-p4, are separated from each other medially (Figs. 3E, 6A). The muscles of the eighth thoracic segment which correspond to the grooming limbs, p5, are crossed, forming an X (Figs. 3E, 6A).

Pleonal muscles. The pleonal muscles are largely reduced. The dorsal (dpm1) and lateral (lpm1) muscles of the first pleonal segment are pronounced and fairly symmetrical (Fig. 4D) while the muscles of the subsequent segments appear to be thinner and more scattered. The fibers of the ventral pleonal muscles (vpm) form a vague, rudimentary layer (Fig. 4F, G).

Ventral nerve cord. The neuromeres of the mandibular, of the first and second maxillar segments and of the thoracic segments are fused with the first pleonal neuromere to form the cephalothoracic ganglion (cg; Figs. 4A, 6A), which is located in the anterior portion of the cephalothorax (thoracic segments th 3 - th6, Fig. 7II). Anteriorly, the cephalothoracic ganglion is connected with the brain (br) via the circumesophageal connectives (cc; Fig. 4A, B). The paired neuropils of the anterior neuromeres (mp; which correspond to the segments of the mouthparts) lie close together, while the neuropils of the posterior neuromeres $(\operatorname{tn} 4-\operatorname{tn} 8$; correspond to the pereiopods) are further apart (Fig. $6 \mathrm{~B}, \mathrm{C}, \mathrm{E})$. Posteriorly, the pleonal ganglia (pn2 - pn6) are connected to the cephalothoracic ganglion via connectives and lie close together within the sixth to seventh thoracic segment (Fig. 7II).

Fig. 2. External integumental structures (volume renderings). A-C. Hapalogaster mertensii: A. Dorsal view; only first and second and part of the third pleonal segment are visible in vivo; B. Ventral view of a female specimen; note the asymmetry of the pleon in females; calcified areas are outlined; tergites are shown by dashed outlines; C. Anteroventral view revealing asymmetrical arrangement of pleopods on the left side only. D. Schematic drawings of a pagurid (I), a hapalogastrid (II), a lithodid (III); pleon in in vivo condition; values beneath red lines show the relative ratios of carapace length to width (width set to 1.0); green values show the relative lengths when the rostrum is included. E. Pagurus hirsutiusculus (Paguridae): ventral view showing separated sternites. F. H. mertensii: ventral view with pleon removed (virtually) to show sternal plastron (blue outline); red dashed line indicates pleon margin; uncalcified areas between sternites outlined with dotted lines. G. Hapalogaster grebnitzkii: anteroventral view; note vertically oriented third thoracic sternites (st3); arrow points to suture. H. H. grebnitzkii: lateral view; dashed line indicates linea anomurica (fracture line during ecdysis). I. H. mertensii: male; ventral view showing bent sac-like pleon; note roughly symmetrical shape of pleon (visible portion corresponds to pleonal segments 4-6) and symmetrical arrangement of calcified areas (tergites, arrowheads). J. H. mertensii: male; posterior view. Abbreviations: cp, carapace; pl, pleon; p1-p5, pereiopods; pl1-pl6, pleonal segments; plas, sterna plastron; plp3-plp5, pleopods; st3-st8, thoracic sternites; t, telson. 

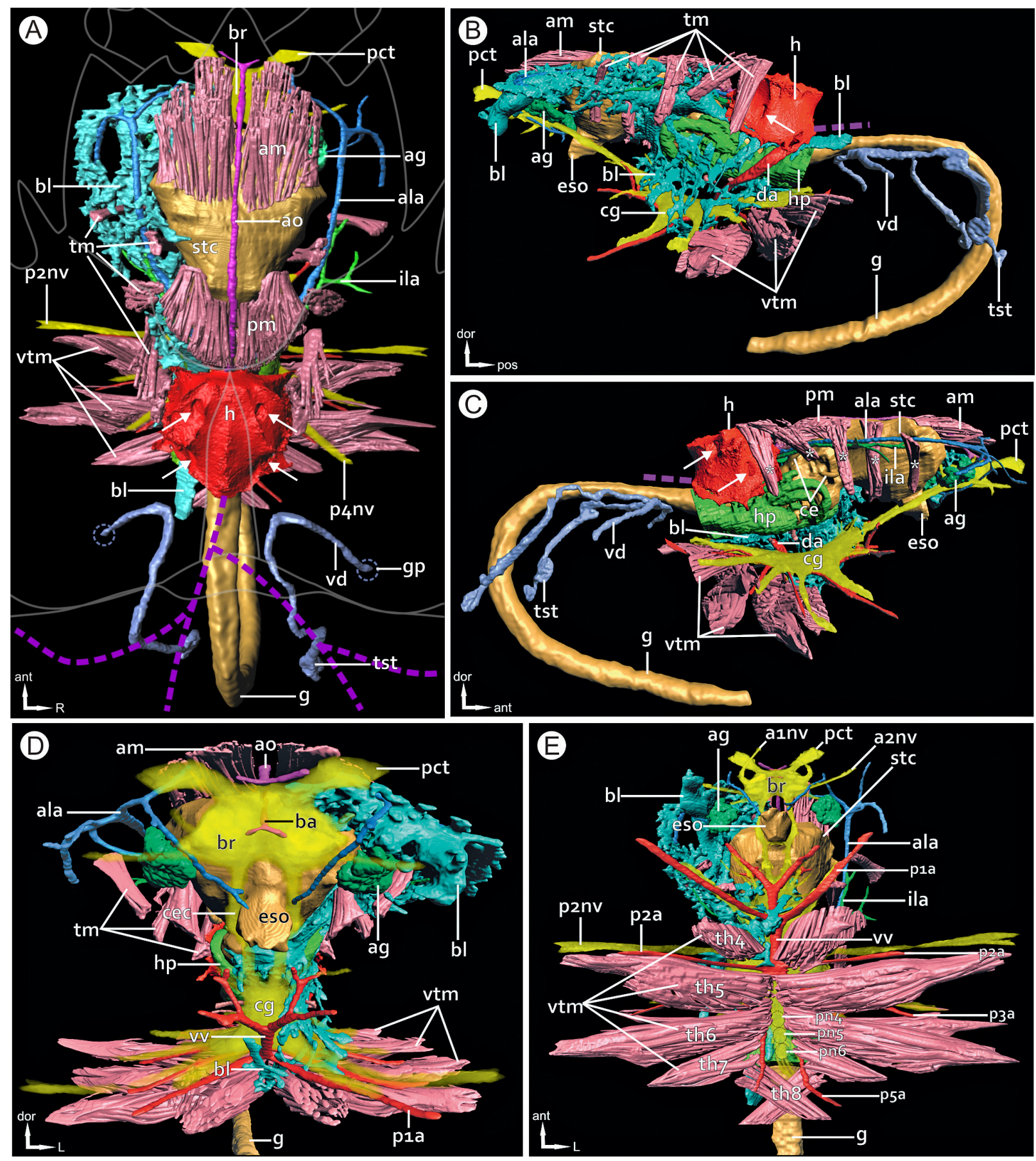

Fig. 3. Spatial relationships between the hemolymph vascular system and other internal organs (surface and volume renderings). The pdf in A contains interactive 3D content. Please click on the figure to activate the content and then use the mouse to rotate the objects. A-E. Hapalogaster mertensii: male; for clarity, only right portion of bladder is shown; arrows in A-C point at ostia; dashed violet line indicates posterior aorta system. A. Dorsal view; B. Left-sided lateral view; C. Right-sided lateral view; D. Frontal view; E. Ventral view. Abbreviations: a2, antennal artery; ag, antennal gland; ala, anterior lateral artery; am, anterior gastric muscle; ao, anterior aorta; bl, bladder; br, brain; ce, cecum; cg, cephalothoracic ganglion; da, descending artery; eso, esophagus; f, fringe artery; g, gut; h, heart; hp, hepatopancreas; ila, inferior lateral arteries; pla-p5a, pereiopodal arteries; pm, posterior gastric muscle; ra, rostral artery; stc, stomach; tm, (vertical) thoracic muscles; tst, testes; vd, vas deferens; vtm, ventral thoracic muscles; vv, ventral vessel. 
Circulatory system. Hemolymph vascular system: All the organs mentioned above are supplied by the hemolymph vascular system (hvs). The terminology used herein is an extended version of that used in the descriptions of the hvs of galatheoid squat lobsters and porcelain crabs published by Keiler et al. (2015).

Heart (Fig. 3): The heart is located dorsally in the cephalothorax, under the carapace and above the anterior portion of the gut, suspended in place by several ligaments (Fig. 3A). The heart is enclosed in a hemolymph-filled space, the pericardial sinus, which is framed laterally by the endopleurites of the endophragmal skeleton, ventrally by the pericardial septum and dorsally by the epidermis of the carapace (not shown). The heart is almost pentagonal in horizontal profile. The ventral side is slightly concave and the dorsal markedly convex. The heart is equipped with three pairs of ostia, slit-like openings which are arranged transversely to the anteroposterior body axis. Two pairs are located dorsally (anterodorsal and posterodorsal ostia) (arrows, Fig. 3A) and one pair is located ventrolaterally (arrows, Fig. 3C). Several muscle strands cross the lumen of the heart (not shown).

Artery Systems: Five artery systems branch off the heart: the unpaired anterior aorta system, the paired anterior lateral artery system, the paired inferior lateral artery system, the unpaired posterior aorta system and the ventral vessel system. The latter consists of the vertical descending artery and the horizontal ventral vessel and its side branches. The proximal portion of all these artery systems lies within the pericardial sinus. Between the heart and each artery system there is a valve.

Anterior aorta system (Figs. 3A, D, 4A-C):

The anterior aorta (ao) emanates anteriorly from the heart, passes the posterior gastric muscles (pm) and runs in anterior direction above the stomach (stc) just below the carapace into the cephalic region, passing the anterior gastric muscles on the way (Fig. 3A). Above the brain, the unpaired brain artery (ba) branches off and descends ventrally into the brain (Figs. 3D, 4B, C), where it turns anteroventrally and bifurcates. Both branches then turn in a posterior direction towards the olfactory lobes of the brain (Fig. 4B). A myoarterial formation (maf) is observable as a slight widening of the anterior aorta directly posterior to the brain artery (Fig. 4C). The anterior aorta continues anteriorly and bifurcates horizontally at a $45^{\circ}$ angle into the optic arteries (oa) which run into the eye stalks (Figs. 3A, 5A).

Anterior lateral artery systems (Figs. 3, 4A, B):

The paired anterior lateral arteries (ala) emanate from the heart directly laterally to the anterior aorta. They run (above the antennal bladder) in an anterior direction at a lateral angle of approximately $45^{\circ}$ and then follow an almost parallel course to the anterior aorta (Figs. 3A, 4A, B). Medially, the anterior lateral arteries give rise to the gastric arteries (not shown) which supply the lateral muscles of the stomach. In the cephalic region, a distinct set of arterial branches (defined by their target organ or region) is present, and can be broken down as follows: Anterolaterally, a branch turns laterally backwards and gives off several smaller arteries which supply the external mandible adductor muscles (xm, Fig. 4A, B). It then continues in a posterior direction (fa, fringe artery) along the branchiostegites. Anteriorly, a side branch runs into the second antennae (a2a, antennal artery). Ventromedially, a branch (aga, antennal gland artery) runs into the antennal gland (Fig. 4A, B). Dorsomedially, a branch emanates and bifurcates into the arteries which supply the rostrum (ra, rostral artery) and the anterior gastric muscles (ama, anterior gastric muscle artery) (Fig. 4B). Distomedially, a branch runs into the first antennae (a1a, antennular artery) (Fig. $4 \mathrm{~B}, \mathrm{C})$.

Inferior lateral artery systems (Figs. 3A, C, E, 4A, B): The paired inferior lateral arteries (ila) branch off directly beneath the anterior lateral arteries and continue their course parallel to and just underneath them (Fig. $6 \mathrm{~B}, \mathrm{C})$, giving rise to several branches which run between the lobes of the antennal bladder. These arteries correspond to the hepatic arteries described in other decapods, but as they do not supply the hepatopancreas in king crabs and pagurid hermit crabs, this new term is suggested.

Posterior aorta system (Fig. 4D-G):

The posterior aorta (pa) emanates from the posteroventral portion of the heart and runs above the gut $(\mathrm{g})$ in a posterior direction. In the eighth thoracic segment, it bifurcates into two equally sized but asymmetrical main arteries, the left (lpa) and right pleonal artery (rpa) (Fig. 4D). Between the first and second pleonal segment, the left pleonal artery bifurcates again into two arteries which are equal in size (arrows, Fig. 4D, E). The left one runs ventro-laterally into the left portion of the pleon, the right one takes a basically median course along the dorsal portion of the pleon. On the way, several small lateral vessels emanate from them which mainly supply the hepatopancreas, the gonads and the gut.

Ventral vessel system (Figs. 3D, E, 6, 7):

The ventral vessel system is made up of the descending artery (da), the ventral vessel (vv) and its side branches, and mainly supplies the ventral nerve cord (vnc), the 


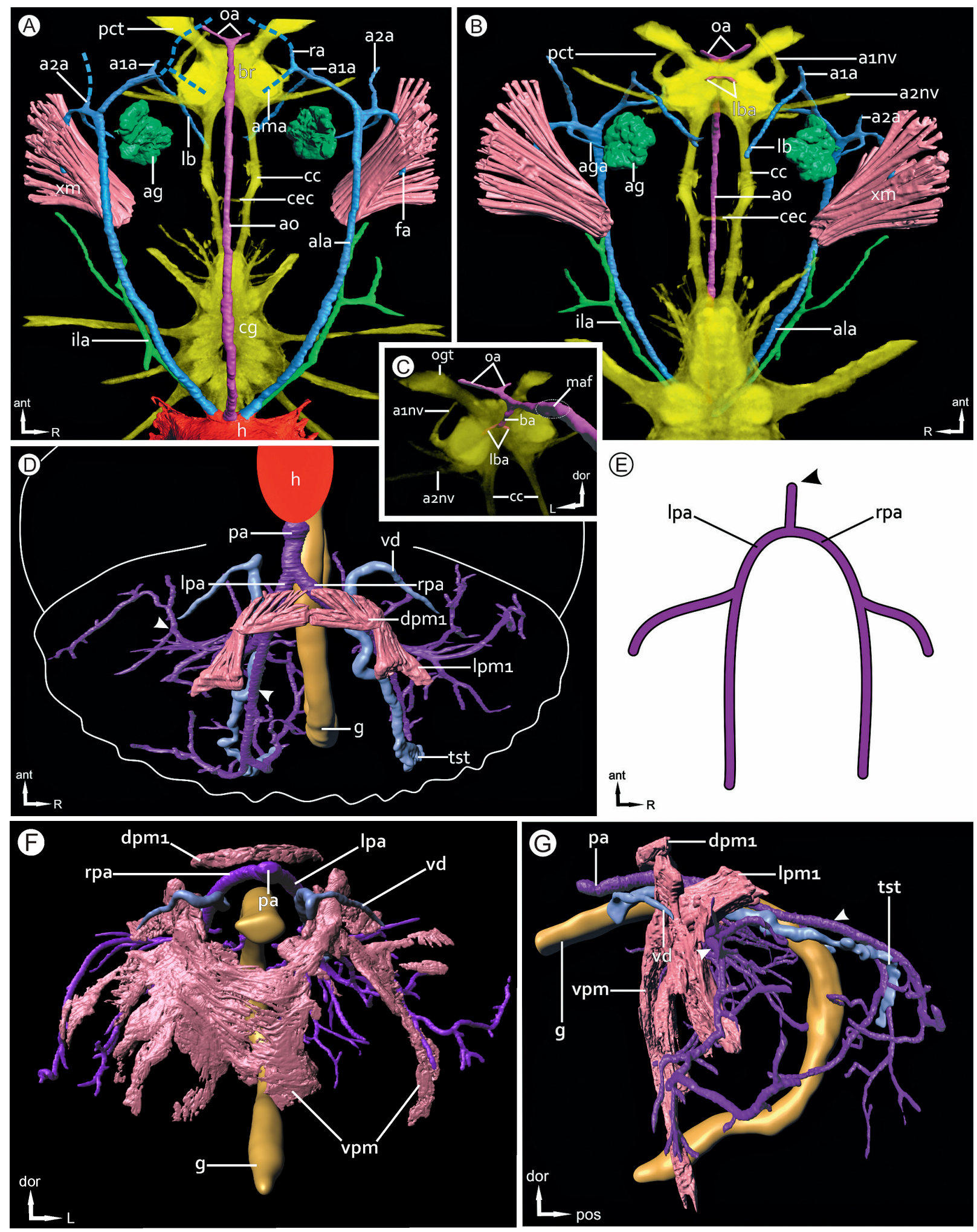


legs (pereiopods p1-p5) and the mouthparts.

The descending artery, which has the greatest diameter of all arteries branching off the heart, emanates from the left side of the posteroventral part of the heart, directly beside the root of the posterior aorta, and runs ventrally (Figs. 3B, 6A, B). In all specimens studied the descending artery crosses the gut on the left (Fig. 3B). The descending artery takes a curved antero-ventral course, pierces the ventral nerve cord between the sixth and seventh thoracic neuromeres $(\operatorname{tn} 6+\operatorname{tn} 7)$ and merges into the ventral vessel below. On the level with the second leg arteries, the descending artery merges with the ventral vessel (p2a) (Fig. 6B). Taking the ventral thoracic muscles (vtm) as a point of reference, the merging point is located roughly between the fourth and fifth thoracic segments (Fig. 7II), under the two transverse thoracic bridges (Fig. 5B). The ventral vessel gives rise to the paired leg arteries (leg arteries, pla-p5a) and to the arteries supplying the mouthparts (Fig. 6E). Before the leg arteries run into their respective leg, they proceed between the cuticular walls formed by the endosternites and endopleurites. The pattern of the leg arteries is variable and asymmetrical in some specimens (Fig. 6DI-III). However, in all specimens, the fifth leg arteries (p5a) emanate from the preceding fourth leg arteries (p4a; Fig. 6DI-III). Anteriorly, the ventral vessel bifurcates into the arteries of the mouthparts (Fig. 6F).

Arterial supply to the mouthparts (Fig. 6E, F): In the cephalic region, the ventral vessel ascends at an angle of $30-45^{\circ}$ (Fig. 6E) and bifurcates anteriorly on a level with endosternites $3 / 4$, giving off successive side branches to the maxillipeds (mpla-mp3a), the first and second maxillae (mx1a-mx2a) and the mandibular arteries (mda) (Fig. 6F).

\section{Discussion}

The hemolymph vascular system in Paguridae and Lithodidae has recently been discussed in the context of carcinization, or evolutionary transformation into a crablike habitus (Keiler et al., 2013). Our present investigations now reveal that the morphology of the hemolymph vascular system in Hapalogaster differs distinctly in several respects from that in Lithodidae, in some respects more closely resembling that in Paguridae. This is not unexpected, since hapalogastrids are hypothesized to be morphologically more 'primitive' within king crabs on account of their less pronounced carcinized shape and smaller size (Richter and Scholtz, 1994).

\section{Evidences of a close relationship between hermit crabs and king crabs}

The artery systems in the dorsal cephalothorax (anterior aorta, anterior lateral arteries and inferior lateral arteries) in Hapalogastridae exhibit the same pattern as in Lithodidae, which in turn closely resembles that found in Paguridae. The asymmetrical course of the pleonal arteries corresponds in pagurids and king crabs, likewise supporting the theory of a close relationship between both groups (for detailed descriptions of the hemolymph vascular system in Lithodidae (see McGaw and Duff, 2008 and Keiler et al., 2013; for Paguridae see Jackson, 1913 and Keiler et al., 2013). Remarkably enough, the sponge-like antennal bladder in Hapalogaster corresponds to the bladder in Pagurus (see Jackson, 1913; pl. 4 , fig. 29) in both shape and extension (the condition is unknown in lithodids), leading us to assume that this state is homologous. Moreover, it is not present in any other anomuran so far studied (Keiler et al., 2015; unpubl. data) and therefore represents another potential synapomorphy of king crabs and pagurids.

New insights into the evolutionary process of carcinization

Previously, we were able to reconstruct the transformations of the internal anatomy as consequence of carcinization in one step only, from the last common ancestor

Fig. 4. Hapalogaster mertensii (surface and volume renderings): dorsal anterior artery systems (A-C) and posterior aorta system (D-G). The pdf in F contains interactive 3D content. Please click on the figure to activate the content and then use the mouse to rotate the objects. A. Dorsal view of anterior cephalothoracic portion. B. Ventral view of anterior cephalothoracic portion. C. Posterolateral view of the anterior aorta system and the brain. D. Dorsal view of the pleonal region; arrowheads indicate main branches of the left pleonal artery. E. Schematic drawing of the posterior aorta system. Only main branches are shown. Arrowhead points to the proximal portion of the posterior aorta. F. Frontal view of the pleonal region. G. Lateral view of pleonal region; arrowheads indicate main branches of the left pleonal artery Abbreviations: a1a, antennular arteries; a2a, antennal arteries; a1nv/a2nv, antennal nerves; ag, antennal gland; aga, antennal gland artery; ama, anterior gastric muscle artery; ba, brain artery; cc, circumesophageal connective; cec, circumesophageal commissure; dpm, dorsal pleonal muscles; fa, fringe artery; g, gut; h, heart; ila, inferior lateral arteries; lba, lateral brain artery; lpa, left pleonal artery; lpm, lateral pleonal muscles; maf, myoarterial formation; oa, optic arteries; pct, protocerebral tract; ra, rostral artery; rpa, right pleonal artery; t, telson; tst, testes; vd, vas deferens. vpm, ventral pleonal muscles. 

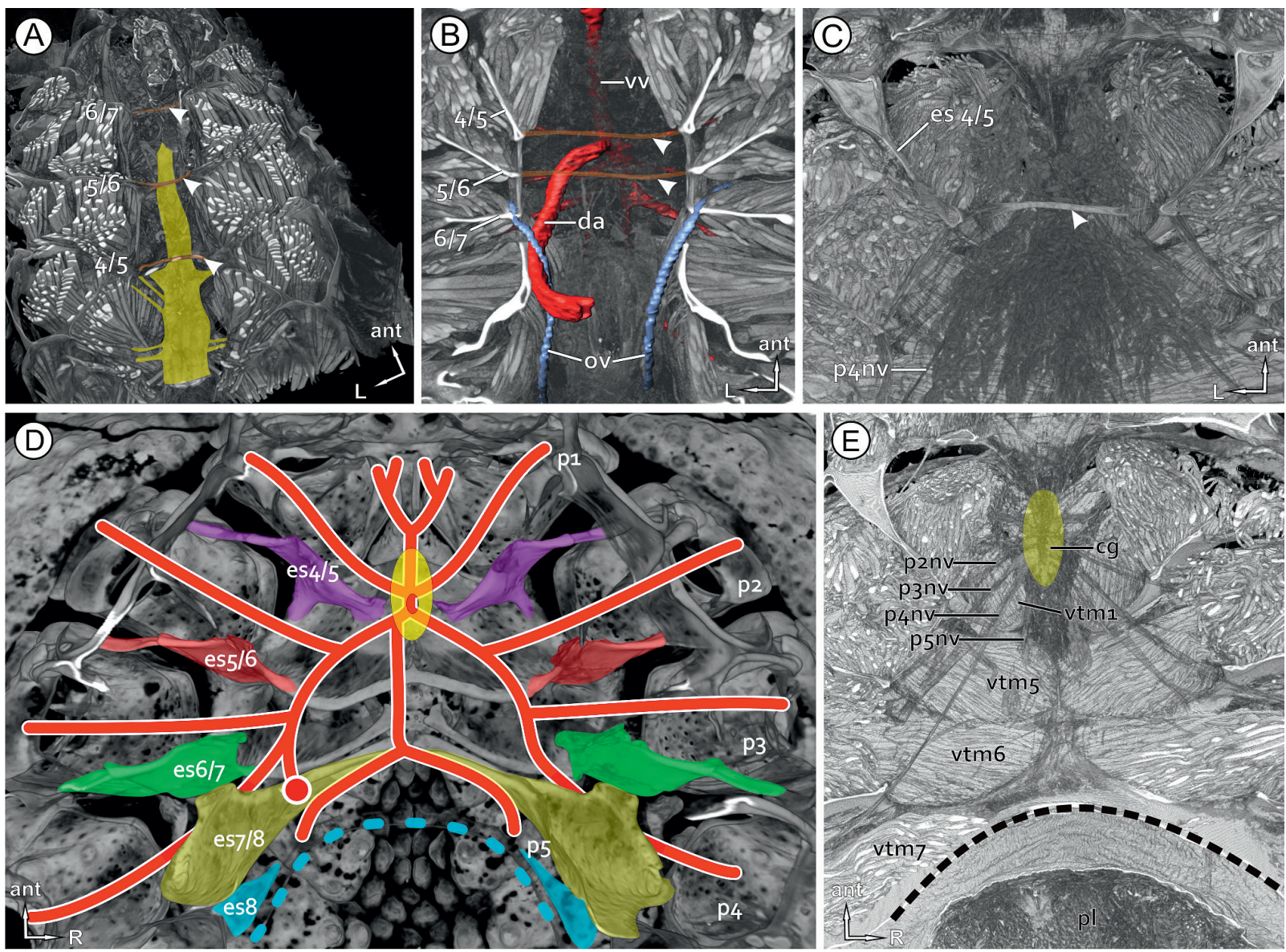

Fig. 5. Volume renderings of virtually cut cephalothorax. A. Pagurus bernhardus (Paguridae): three thoracic bridges (arrows); anterodorsal view; yellow area indicates ventral nerve cord B. Hapalogaster mertensii: two thoracic bridges (arrowheads), reconstructed ventral vessel system and oviducts (surface renderings); dorsal view. C. Lithodes aequispinus (Lithodidae): one thoracic bridge (arrowhead); dorsal view. D. Lithodes santolla (Lithodidae): virtually cut specimen; endosternites are colored; ventral vessel system (red) and cephalothoracic ganglion (yellow ellipse) lie between endosternites. E. L. aequispinus: spatial relationships between cephalothoracic ganglion (yellow overlay) and ventral thoracic muscles (vtm); black dashed lines indicates posterior margin of plastron. Abbreviations: cg, cephalothoracic ganglion; da, descending artery; es, endosternites; od, oviducts; p1-4, pereiopods; p2nv-p5nv, leg nerves; pl, pleon; vtm5-7, ventral thoracic muscles; vv, ventral vessel.

(LCA) of Paguridae and king crabs whose external and internal anatomy was most probably pagurid-like (Keiler et al., 2013) to the last common ancestor of Lithodidae (represented by the lithodid genera Lithodes and Paralomis). The present study now allows including an intermediate step - the LCA of Hapalogastridae and Lithodidae (Fig. 8). Since hapalogastrids and lithodids have undergone the same period of evolution beginning with their calculated divergence 18 million years ago (see Bracken-Grissom et al., 2013), the exact morphology of this ancestor neither corresponds to one group or to the other. We consider all characters of Hapalogastridae which are either shared with Paguridae (plesiomorphies) or with Lithodidae (synapomorphies) as belonging to the ground pattern of the LCA of Hapalogastridae and Lithodidae. Characters which are neither shared with pagurids nor lithodids are autapomorphies of hapalogastrids. The process of carcinization proper was completed already in the lineage from the LCA of Paguridae and king crabs towards the LCA of Hapalogastridae and Lithodidae (Fig. 8). Internal changes which are coherent with (i.e. structurally dependent on) external changes into a crab-like habitus (see Keiler et al., 2013, 2015 for further details) logically appeared in the same lineage. 

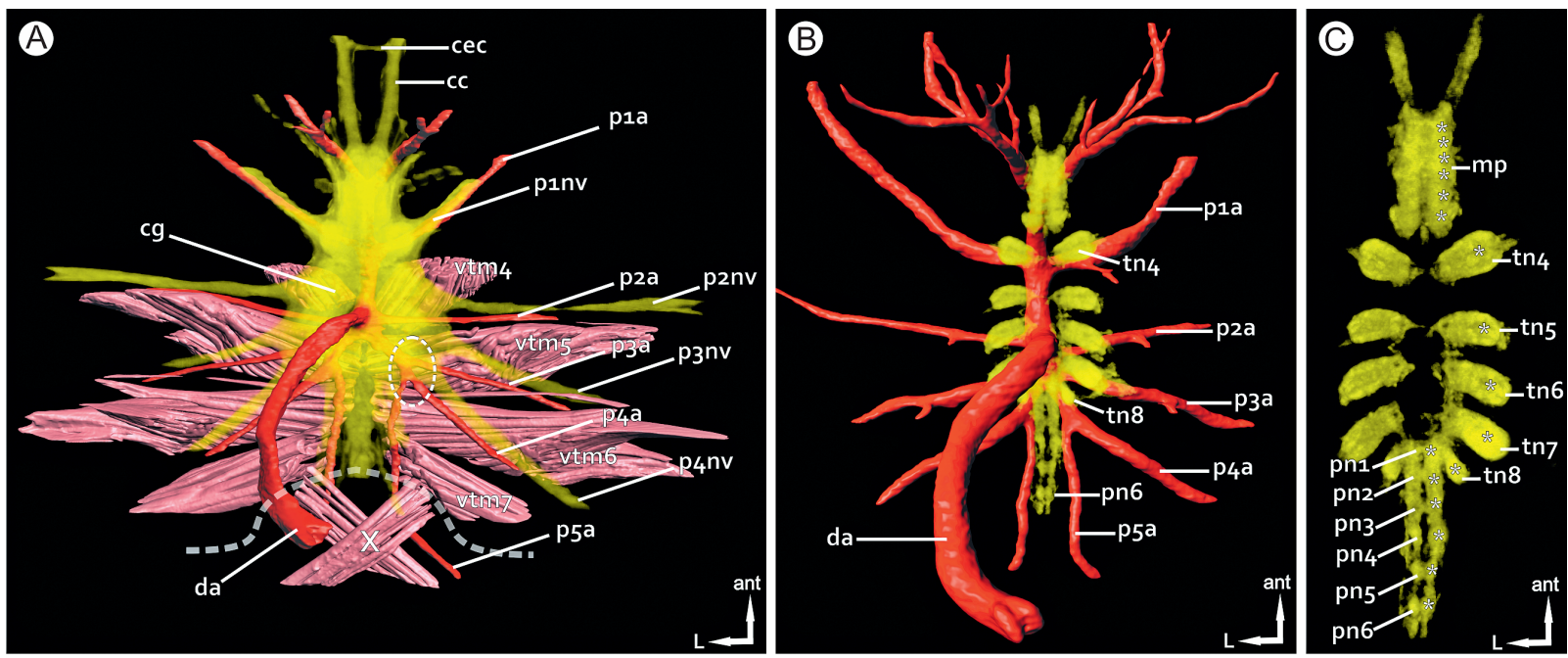

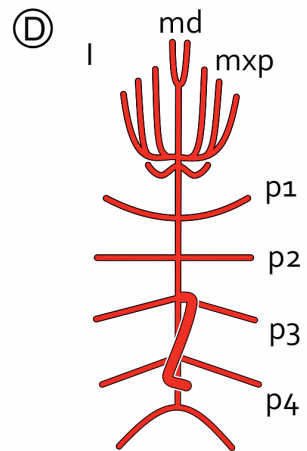

Pagurus

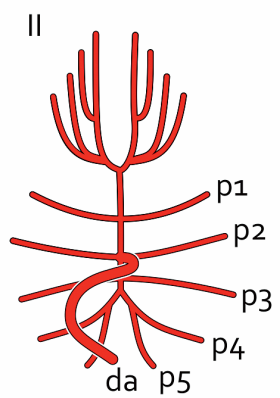

da P5

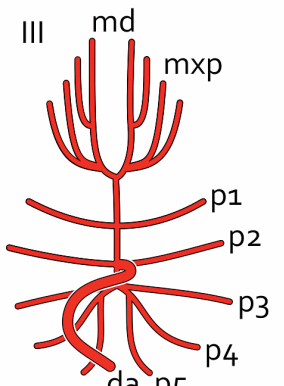

da $\mathrm{p5}$

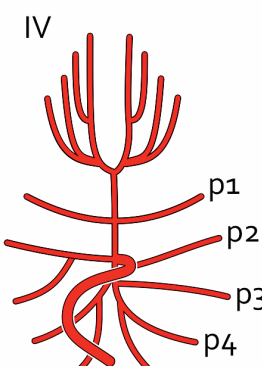

da $\mathrm{P5}$

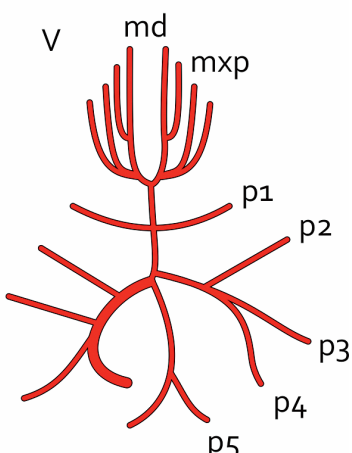

P5
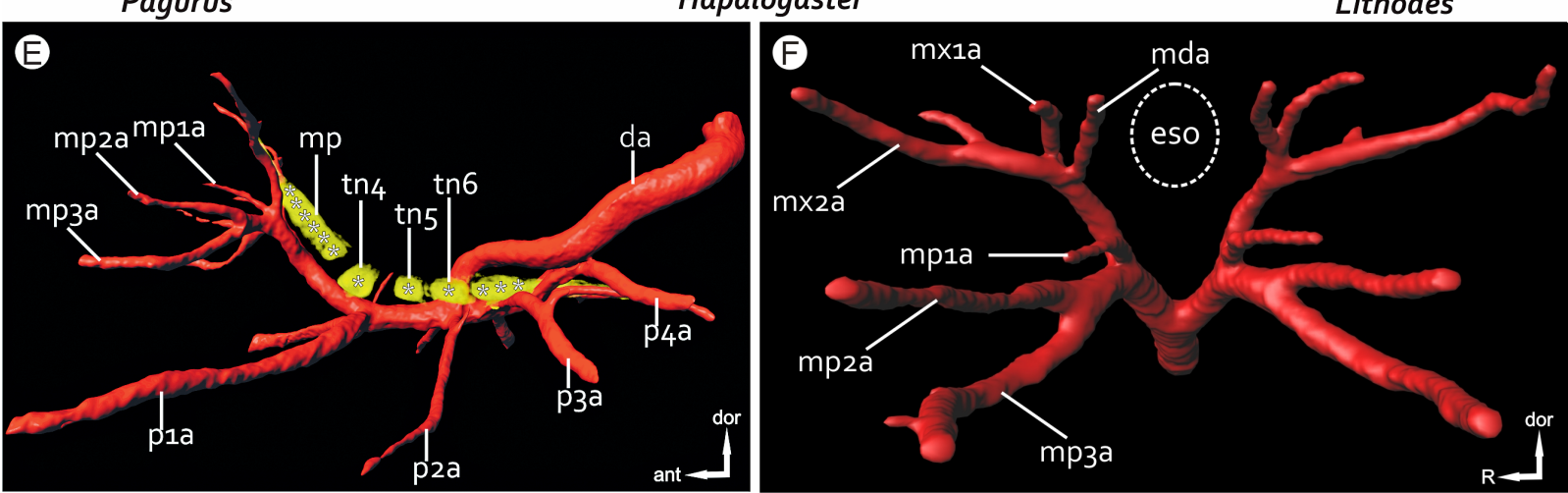

Fig. 6. Spatial relationships between the organ systems of the ventral body side (surface and volume renderings). The pdf in F contains interactive 3D content. A-C. Hapalogaster mertensii: A. dorsal view of ventral thoracic muscles (pink), ventral vessel system (red) and nervous system (yellow); dashed semi-transparent white line indicates posterior margin of plastron; B. Dorsal view of ventral vessel system (red) and neuropil clusters (yellow) of the ventral nerve cord; descending artery (da) merges with the ventral vessel on a level with the second leg arteries (p2a); C. Neuropil clusters (asterisks) of ventral nerve cord. D. Schematic drawing of the ventral vessel system in Pagurus (I), Hapalogaster (II-IV), Lithodes (V); branching pattern of leg arteries p2a-p5a in Hapalogaster is variable. E-F. H. mertensii: E. Lateral view of ventral vessel system and neuropil clusters (asterisks) of the ventral nerve cord; F. Frontal view of ventral vessel system showing the arteries supplying the mouthparts. Color code: pink, ventral thoracic muscles; light blue, sternal plastron; dark blue, endosternites; red, ventral vessel system; yellow, neuropil clusters of the ventral nerve cord. Abbreviations: cec, circum esophageal commissure; cg, cephalothoracic ganglion; da, descending artery; eso, esophagus; mp, neuromers of the mouthparts; p1-p5, legs (pereiopods); pla-p5a; leg arteries; p1 nv-p5nv, leg nerves; pn1-pn6, pleonal neuromers; pvv, posterior ventral vessel; tn4-tn8, thoracic neuromers; vtm, ventral thoracic muscles; vv, ventral vessel; $\mathrm{X}$, crossed ventral muscles of the $8^{\text {th }}$ thoracic segment. 

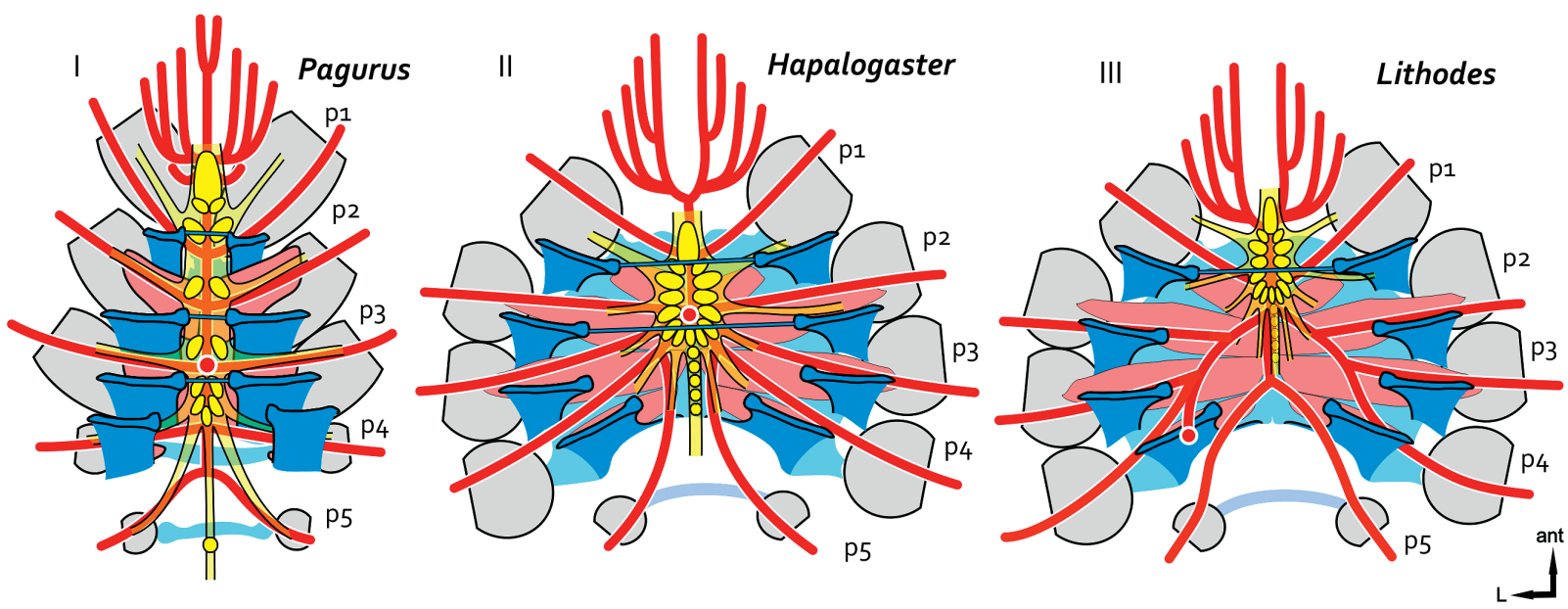

Fig. 7. Schematic drawing of the ventral organs in species of Pagurus (I), Hapalogaster (I), Lithodes (III) in dorsal view. The condition in Pagurus represents the state in the last common ancestor of hermit crabs and king crabs (LCA PK), that in Hapalogaster represents the state in the last common ancestor of hapalogastrids and lithodids (LCA HL). Color code: pink, ventral thoracic muscles; light blue, sternal plastron; dark blue, endosternites; red, ventral vessel system; yellow, neuropil clusters of the ventral nerve cord.

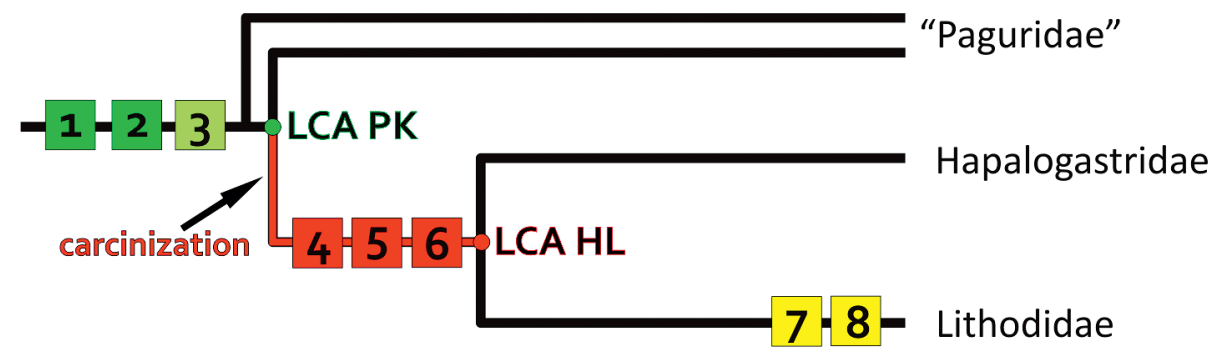

Fig. 8. Simplified phylogenetic tree (note that Paguridae are most probably paraphyletic with respect to king crabs) displaying anatomical characteristics and evolutionary morphological changes in the different lineages. Abbreviations: LCA PK, last common ancestor of Paguridae and king crabs; LCA HL, last common ancestor of Hapalogastridae and Lithodidae.

\section{Transformations of the pleon}

Due to the weak calcification in pleonal segments pl4pl6, the pleon in Hapalogaster is rather sac-like and differs from the more compact and more calcified pleon in lithodids. In this, hapalogastrids still resemble hermit crabs, which possess a sac-like although markedly coiled pleon. In our view, the well calcified tergite plates (and nodules) in Lithodidae represents a secondary condition (contrary to McLaughlin et al., 2004). That the condition in pagurids is the plesiomorphic one is the necessary result of the nested position of king crabs within hermit crabs. McLaughlin et al. (2004) might be correct that the developmental sequence of the formation of tergite plates in king crabs might not be entirely congruent with the hypotheses of Bouvier (1895) and Boas (1924). What is shared by pagurids and king crabs, however, is the separation of tergite plates which in pagurids (summarized in McLaughlin et al., 2004) and apparently in hapalogastrids (Crain and McLaughlin, 2000) is the result of decalcification.

As in species of Pagurus, the dorsal pleonal musculature in $H$. mertensii is substantially reduced and pronounced muscular bundles are restricted to the first pleonal segment. The ventral pleonal musculature in $H$. mertensii, however, is thin and arranged in a thin layer of fibers which appears patchy and disorganized (Fig. 4F, G) in comparison to the much thicker and more compact ventral pleonal muscle in species of Pagurus (see fig. 6A in Keiler et al., 2013), which is responsible for the rapid withdrawal into the gastropod shell (Stephens, 1986). Apart from this, the transformation of the internal pleonal morphology which took place in the lineage from the LCA of Paguridae and king crabs 

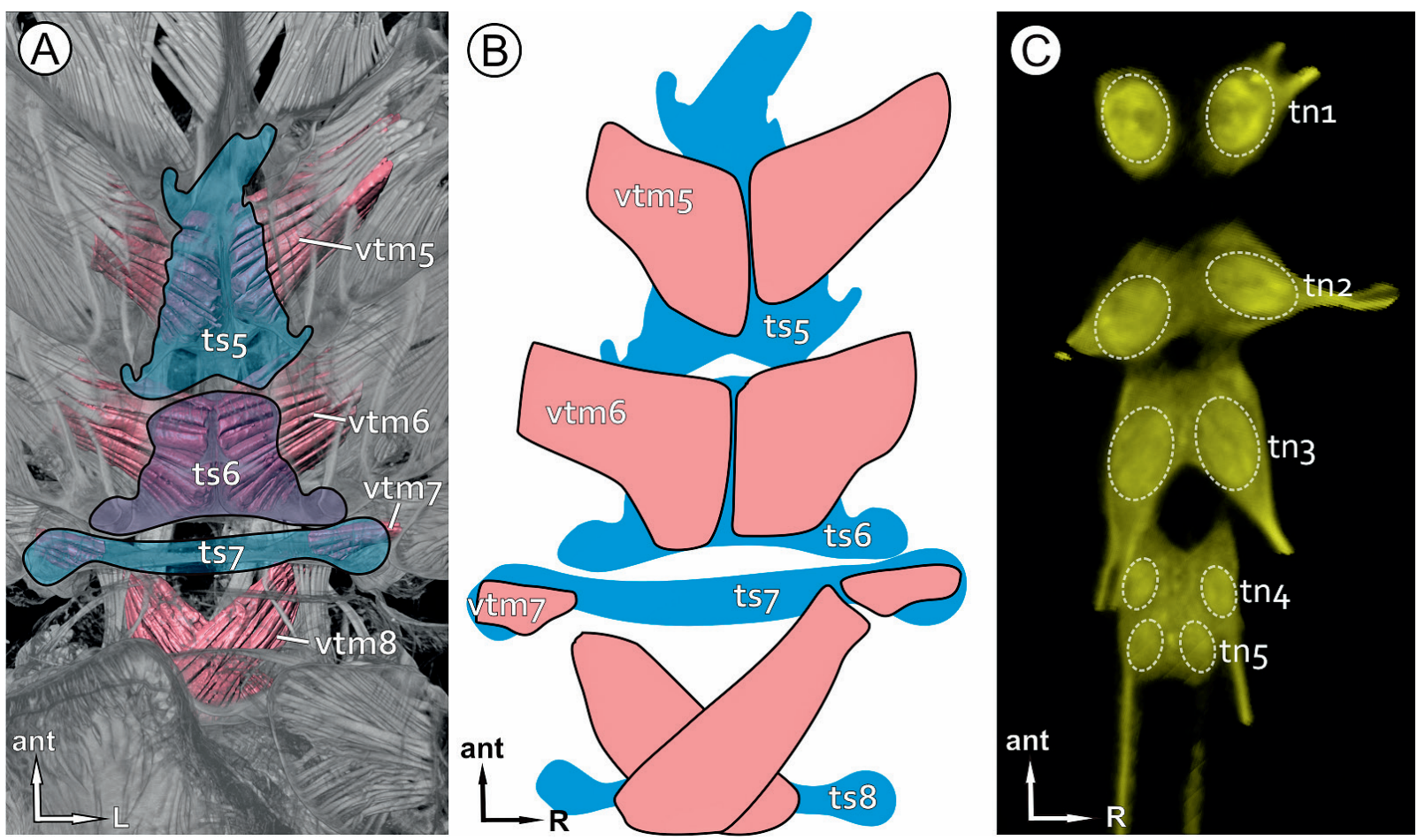

Fig. 9. A-B. Pagurus bernhardus (Paguridae): A. Ventral view of cephalothorax revealing spatial relationships between ventral thoracic muscles and sternites (transparent overlay). Volume and surface renderings. B. Schematic drawings of ventral thoracic muscles (pink) and sternites (blue) as seen in A in dorsal view. C. Pagurus pubescens (Paguridae): dorsal view of spatially divided neuropils (dashed semi-transparent white circles) of cephalothoracic ganglion (horizontally sectioned); neuropil of first pleonal neuromer hidden between neuropils tn5. Abbreviations: tn1-5, thoracic neuromers; ts5-8, thoracic sternites; vtm5-8, ventral thoracic muscles.

towards king crabs (or the LCA of Hapalogastridae and Lithodidae, respectively) was relatively minor. Based on the findings in Pagurus (Keiler et al., 2013) and Hapalogaster, the posterior aorta in the LCA of Hapalogastridae and Lithodidae bifurcated into two asymmetrical branches of equal diameter, the left and right pleonal artery, representing the situation in the LCA of Paguridae and king crabs. In the lineage from the LCA of Paguridae and king crabs towards the LCA of Hapalogastridae and Lithodidae, the left pleonal artery developed another bifurcation into two arteries of equal size (the ventro-lateral and the dorso-medial artery; arrowheads in Fig. 4D, G). This may be functionally interpreted as an adaptation which was needed to provide sufficient hemolymph to the broadened pleon. Our findings for Hapalogaster support the previously hypothesized homology of the branches of the posterior aorta system in pagurids and lithodids (Keiler et $a l ., 2013)$. In terms of position and course, the distal portion of the 'left pleonal artery' in lithodids corresponds with the ventro-lateral branch in $H$. mertensii, while the slightly thinner 'medial pleonal artery' in lithodids corresponds to the dorso-medial artery in $H$. mertensii.

Transformations of the ventral cephalothorax-coherences in the course of carcinization

The transformations of the ventral cephalothorax which took place in the lineage from the LCA of Paguridae and king crabs towards the LCA of Hapalogastridae and Lithodidae basically affected five components which, in varying respects, are structurally dependent on each other (i.e. coherent). These are a) the sternites, b) the endosternites, c) the ventral thoracic muscles, d) the ventral nerve cord and e) the ventral vessel system.

a) In the lineage from the LCA of Paguridae and king crabs (Fig. 9B) towards the LCA of Hapalogastridae and Lithodidae, thoracic sternites 4-7 fused to form a broad sternal plastron. The antero-ventral bend in the pleon gave the plastron its distinct concave posterior emargination.

b) The endophragmal skeleton, which appears to have been particularly affected by the transformational 
processes of carcinization (Keiler et al., 2013,2015), is relatively similar in hapalogastrids and lithodids but differs distinctly between pagurids and king crabs. The emergence of the broad sternal plastron resulted in an increase in the medial distance between the endosternites (Keiler et al., 2013; see Fig. 5D), and a successive reduction in the number of transverse thoracic bridges seems likely to have occurred in the lineage towards Lithodidae (Figs. 5A-C, 7).

c) The size and spacing of the sets of ventral thoracic muscles also changed due to modifications in the sternites. On the one hand, the muscles moved closer together along the body axis due to the posterior emargination of the plastron. On the other hand, the medial distance between the muscles increased as a result of the broadening of the ventral cephalothorax (Fig. 5E). The most substantial modification, however, affected the ventral thoracic muscles of the fourth pereiopods (= $v t m 7)$. The fourth pereiopods evolved from short limbs providing grip in a gastropod shell in the LCA of Paguridae and king crabs to walking legs in king crabs (Richter and Scholtz, 1994; Keiler and Richter, 2011). The ventral thoracic muscles, changed from small bundles in the LCA of Paguridae and king crabs (Fig. 9A) to relatively large bundles in king crabs.

d) The ventral nerve cord underwent a marked change in arrangement and position in the lineage from the LCA of Paguridae and king crabs (Fig. 9C) toward the LCA of Hapalogastridae and Lithodidae (compare schematic drawings I and II in Fig. 7). The cephalothoracic ganglion became more planar due to the planar inner surface of the plastron, the cephalothoracic ganglion became distinctly compact and the pleonal ganglia were shifted anteriorly. The transformation of the pleonal ganglia was apparently coherent with functionalmorphological changes in the pleon and the pleonal muscles. In hermit crabs, the pronounced ventral pleonal muscles are responsible for rapid withdrawal into the gastropod shell (Stephens, 1986). This function and biological role were lost in the evolution of king crabs, whose pleons are bent and remain in an idle state most of the time. Although it was already compact and had shifted anteriorly, the transformation of the ventral nerve cord continued in the lineage from the LCA of Hapalogastridae and Lithodidae to Lithodidae. The cephalothoracic ganglion in lithodids is situated further anterior (the posterior margin is located in the fourth thoracic segment) and proportionally smaller (Figs. 5E, 7III).

In the context of the changes in the fourth pereiopods it should be pointed out that, in contrast to the preced- ing neuropils, the neuropils of the seventh and eighth thoracic and first pleonal neuromer were tightly packed and rather small in the LCA of Paguridae and king crabs (as in Pagurus; Fig. 9C, see also Bouvier, 1889 plate 7; Stephens, 1986). This condition changed in the lineage towards the LCA of Hapalogastridae and Lithodidae, resulting in the distinctly larger and more separated neuropils corresponding to the fourth pereiopods. This, in turn, corresponds secondarily with the neuropil arrangement in other anomurans (Keiler et al., 2015, unpubl. data), whose fourth leg is developed as a "normal' walking leg.

e) The distinct left-handed curve in the course of the descending artery in $H$. mertensii (Figs. 5B, 6A, B) represents the condition in the LCA of Hapalogastridae and Lithodidae and corresponds with the course of this artery in Lithodidae (Marukawa, 1933; McGaw and Duff, 2008; Keiler et al., 2013). This distinct curve is most likely the result of the comparatively large proximal main ducts of the hepatopancreas and the gut, which the descending artery skirts (Fig. 3B). Variability notwithstanding, the fourth and fifth leg arteries in $H$. mertensii always possess a common root which emanates relatively close to the third leg arteries. The same pattern we assume for the LCA of Hapalogastridae and Lithodidae, meaning that a shift in artery roots appeared in the lineage from the LCA of Paguridae and king crabs toward the LCA of Hapalogastridae and Lithodidae. Remarkably, the branching pattern of the leg arteries differs significantly between $H$. mertensii and Lithodidae, suggesting a second transformational step in the lineage from the LCA of Hapalogastridae and Lithodidae towards lithodids which resulted in a fusion of arteries p2a-p4a. The pronounced curve of the descending artery in the LCA of Hapalogastridae and Lithodidae and the anterior shift in the cephalothoracic ganglion presumably both represented prerequisites for the subsequent condition in Lithodidae, in which the descending artery skirts around the cephalothoracic ganglion (Keiler et al., 2013). This in turn led to the gently sloping arterial course in lithodids, which presumably facilitated the fusion of the leg arteries and the descending artery. On the other hand, it could be said that the loss of the bottleneck in the form of the pierced ganglion made the new condition a prerequisite for the high level of variability in the branching pattern of the leg arteries seen in some lithodids (Keiler et al., 2013). The distance between the endosternites (i.e. the lack of 'guard rails'), however, seems to constitute a more important prerequisite for the presence of variability (Keiler et al., 2013, 2015). 
Table 1. Conditions of selected anatomical features in Paguridae, Hapalogastridae and Lithodidae. Correspondences are color-coded.

\begin{tabular}{|c|c|c|}
\hline Paguridae & Hapalogastridae & Lithodidae \\
\hline unpaired mandibular artery & mouthpart arteries with proximal bifurcation & mouthpart arteries with proximal bifurcation \\
\hline leg arteries separated & leg arteries fused (p4a and p5a) & leg arteries fused (p2a, p3a and p4) \\
\hline descending artery with angled course & descending artery with curved course & descending artery with curved course \\
\hline $\begin{array}{l}\text { descending artery pierces } \\
\text { cephalothoracic ganglion }\end{array}$ & $\begin{array}{l}\text { descending artery pierces } \\
\text { cephalothoracic ganglion }\end{array}$ & $\begin{array}{l}\text { descending artery skirts around } \\
\text { cephalothoracic ganglion }\end{array}$ \\
\hline pleonal ganglia segmentally arranged & pleonal ganglia condensed & pleonal ganglia condensed \\
\hline cephalothoracic ganglion elongated & cephalothoracic ganglion condensed & cephalothoracic ganglion condensed \\
\hline $\begin{array}{l}\text { posterior aorta bifurcates into } \\
\text { asymmetrical pleonal arteries }\end{array}$ & $\begin{array}{l}\text { posterior aorta bifurcates into } \\
\text { asymmetrical pleonal arteries }\end{array}$ & $\begin{array}{l}\text { posterior aorta bifurcates into } \\
\text { asymmetrical pleonal arteries }\end{array}$ \\
\hline left pleonal artery unfurcated & $\begin{array}{l}\text { left pleonal artery bifurcates into a } \\
\text { symmetrical arteries }\end{array}$ & $\begin{array}{l}\text { left pleonal artery bifurcates into } \\
\text { asymmetrical arteries }\end{array}$ \\
\hline hepatopancreas located largely in the $p$ & hepatopancreas located largely in the pleon & hepatopancreas located largely in the pleon \\
\hline gonads located largely in the pleon & gonads located largely in the pleon & gonads located largely in the pleon \\
\hline sponge-like antennal bladder & sponge-like antennal bladder & condition unknown \\
\hline pleonal segments $1-3$ poorly calcified & pleonal segments $1-3$ calcified & pleonal segments $1-3$ calcified \\
\hline pleonal segments 4-6 poorly calcified & pleonal segments $4-6$ poorly calcified & pleonal segments 4-6 calcified \\
\hline
\end{tabular}

Hapalogaster - the connecting link between hermit crabs and lithodid king crabs?

Hapalogaster resembles both pagurids and lithodids, not only in external morphology but, as we have shown here for H. mertensii, also in certain internal anatomical features (see Tab. 1). Compared to lithodids, hapalogastrids possess more anatomical characters that are plesiomorphic, meaning that these characters have not changed since the LCA of Paguridae and king crabs (e.g. the weakly calcified last pleonal segments or the piercing of the cephalothoracic ganglion by the descending artery). Furthermore, Hapalogaster exhibits anatomical conditions which can be interpreted as less derived than those in lithodids, e.g. the cephalothoracic ganglion, which is more anterior and more compact than in pagurids, but not as small or as far anterior as in lithodids. In this and other respects, Hapalogaster can be interpreted as representing an evolutionarily intermediate form, i.e. a connecting link between hermit crabs and lithodid king crabs.

\section{Acknowledgements}

The authors would like to thank Christoph Noever (University of Bergen) for providing the H.mertensii and some of the Pagurus specimens. Craig Staude (Friday Harbor Labs) is thanked for his contribution of $\mathrm{H}$. grebnitzkii specimens. The authors would also like to thank the staff of the Electron Microscopy Centre (University of Rostock) for assistance with critical point drying. Peter Michalik and his colleagues (Zoological Institute, University of Greifswald) are thanked for providing their microCT for some scans. Lucy Cathrow helped to improve the English of the text. Finally, thanks go to the authors' colleagues at the Zoological Institute of the University of Rostock and three anonymous reviewers for comments and suggestions which improved the manuscript; and the German Science Foundation (DFG) for funding this study (grant numbers WI 3334/1-2 and 3334/3-1).

\section{References}

Anker A, Paulay G. 2013. A remarkable new crab-like hermit crab (Decapoda: Paguridae) from French Polynesia, with comments on carcinization in the Anomura. Zootaxa 3722: 283-300. 
Ahyong ST, Schnabel KE, Maas EW. 2009. Anomuran phylogeny: New insights from molecular data. Pp. 399-414 in: Martin JW, Crandall KA, Felder DL, eds, Crustacean Issues: Decapod Crustacean Phylogenetics. Rotterdam: A.A. Balkema.

Boas JEV. 1880a. Studier over Decapodernes Slaegtskabsforhold. Det Kongelige Danske Videnskabernes Selskabs Skrifter: Naturvidenskabeli og Mathematisk Afdeling 1(2): 27-210.

Boas JEV. 1880b. Lithodes und Pagurus. Zoologischer Anzeiger 3: $349-352$

Borradaile LA. 1916. Crustacea. Part II. Porcellanopagurus: An instance of carcinization. Natural History Report. Zoology 3: $111-126$

Bouvier EL. 1889. Le système nerveux des crustacés décapodes et ses rapportsavec l'appareil circulatoire. Annales des Sciences Naturelle Zoologie 7: 73-106.

Bouvier EL. 1895. Recherches sur les affinites des Lithodes \& des Lomis avec les Pagurides. Annales des Sciences Naturelle Zoologie 18: 157-213.

Bracken-Grissom HD, Cannon ME, Cabezas P, Feldmann RM, Schweitzer CE, Ahyong ST, Felder DL, Lemaitre R, Crandall KE. 2013. A comprehensive and integrative reconstruction of evolutionary history for Anomura (Crustacea: Decapoda). BMC Evolutionary Biology 13: 128.

Brandt JF. 1850. Vorläufige Bemerkungen über eine aus zwei noch unbeschriebenen Gattungen und Arten gebildete Unterabtheilung (Hapalogastrica) der Tribus Lithodina, begleitet von einer Charakteristik der eben genannten Tribus der Anomura. Bulletin de la Classe physic-mathématique de l'Académie imperial des sciences de Saint-Pétersbourg. 8: 266-269.

Chu KH, Tsang LM, Ma KY, Ng PKL. 2009. Decapod Phylogeny: What can protein-coding genes tell us? Pp. 89-99 in: Martin JW, Crandall KA, Felder DL, eds, Crustacean Issues, Vol. 18: Decapod Crustacean Phylogenetics. Boca Raton: CRC Press.

Crain JA, McLaughlin PA. 2000. Larval and early juvenile development in the Lithodidae (Decapoda: Anomura: Paguroidea) reared under laboratory conditions. 2. Hapalogastrinae: Placetron wosnessenskii Schalfeew, 1892, with notes on comparative development within the subfamilies of the Lithodidae. Invertebrate Reproduction \& Development 37: 113-127.

Cunningham CW, Blackstone NW, Buss LW. 1992. Evolution of king crabs from hermit-crab ancestors. Nature 355: 539-542.

Jackson HG. 1913. Eupagurus. LMBC Memoirs on typical British Marine Plants and Animals 21: 1-79.

Jaszkowiak K, Keiler J, Wirkner CS, Richter S. in press. The mouth apparatus of Lithodes maja (Crustacea: Decapoda) form, function and biological role. Acta Zoologica.

Keiler J, Richter S. 2011. Morphological diversity of setae on the grooming legs in Anomala (Decapoda: Reptantia) revealed by scanning electron microscopy. Zoologischer Anzeiger 250: 343-366.

Keiler J, Richter S, Wirkner CS. 2013. Evolutionary morphology of the hemolymph vascular system in hermit and king crabs
(Crustacea: Decapoda: Anomala). Journal of Morphology 274: 759-788.

Keiler J, Richter S, Wirkner CS. 2015. Evolutionary morphology of the organ systems in squat lobsters and porcelain crabs (Crustacea: Decapoda: Anomala): An insight into carcinization. Journal of Morphology 276: 1-16.

Marukawa H. 1933. Biological and fishery research on Japanese king crab Paralithodes camtschatica (Tilesius). Journal of the Imperial Fisheries Experimental Station 4: 1-52.

McGaw IJ, Duff SD. 2008. Cardiovascular system of anomuran crabs, genus Lopholithodes. Journal of Morphology 269: 1295-1307.

McLaughlin PA, Lemaitre R, Tudge CC. 2004. Carcinization in the Anomura - fact or fiction? II.Evidence from larval, megalopal and early juvenile morphology. Contributions to Zoology 73: 165-205.

McLaughlin PA, Lemaitre R, Sorhannus U. 2007. Hermit crab phylogeny: A reappraisal and its "fall-out". Journal of Crustacean Biology 27: 97-115.

Morrison CL, Harvey AW, Lavery S, Tieu K, Huang Y, Cunningham CW. 2002. Mitochondrial gene rearrangements confirm the parallel evolution of the crab-like form. Proceedings of the Royal Society of London Series B: Biological Sciences Volumes 269: 345-350.

Reimann A, Richter S, Scholtz G. 2011. Phylogeny of the Anomala (Crustacea, Decapoda, Reptantia) based on the ossicles of the foregut. Zoologischer Anzeiger 250: 316-342.

Richter S, Scholtz G. 1994. Morphological evidence for a hermit crab ancestry of lithodids (Crustacea, Decapoda, Anomala, Paguroidea). Zoologischer Anzeiger 233: 187-210.

Schnabel KE, Ahyong ST, Maas EW. 2011. Galatheoidea are not monophyletic - Molecular and morphological phylogeny of the squat lobsters (Decapoda: Anomura) with recognition of a new superfamily. Molecular Phylogenetics and Evolution 58: 157-168.

Scholtz G. 2014. Evolution of crabs - history and deconstruction of a prime example of convergence. Contributions to Zoology 83: 87-105.

Stephens PJ. 1986. The fused thoracic-abdominal ganglion of the hermit crab (Pagurus pollicaris): Neuromuscular relationships in the thoracic and abdominal flexor muscles. Journal of Experimental Biology 123: 201-216.

Stevens BG. 2014. The King of Crabs. Pp. ix-x in: Stevens GB, ed, King crabs of the world. Biology and Fisheries Management. Boca Raton: CRC press.

Tsang LM, Ma KY, Ahyong ST, Chan TY, Chu KH. 2008. Phylogeny of Decapoda using two nuclear protein-coding genes: Origin and evolution of the Reptantia. Molecular Phylogenetics and Evolution 48: 359-368.

Tsang LM, Chan TY, Ahyong ST, Chu KH. 2011. Hermit to king, or hermit to all: multiple transitions to crab-like form from hermit crab ancestors. Systematic Biology 60: 616-629.

Received: 7 October 2014

Revised and accepted: 3 February 2015

Published online: 4 August 2015

Editor: R. Vonk 


\section{Online supplementary information}

S1. Studied specimens. ZSRO\#, collection number of the Zoological Collection of the University of Rostock; m, male; f, female; inj, injection: m2, Mercox 2 resin; pu4, PU4 resin; fix, fixation: PFA, paraformaldehyde; ga, n.a., not determinedglutaraldehyde; kar, Karnofsky's fixative; CT, micro computer tomography; n.a., not determined.

S2. Lithodes maja (Lithodidae): A. Ventral view; pleon virtually cut to show sternal plastron (outlined in blue); red dashed line indicates pleon margin; uncalcified areas between sternites shown with dotted outlines. B. Anteroventral view; note the vertically oriented third thoracic sternites (st3); arrow indicates suture. Abbreviations: cp, Carapace; mxp3, maxilliped 3; pl-5, pereiopods; pl, pleon; pl3, third pleonal segment; pla, sternal plastron; st3-7; sternites; t, telson. 